\title{
Contemporaneidade neoliberal e epistemologias afrodiaspóricas Diálogos críticos em busca de novos devires
}

\author{
Alexandre Bonetti Lima \\ Universidade Estadual de Londrina, Brasil \\ bonetti@uel.br
}

\section{Resumo}

Este ensaio tem por objetivo traçar considerações críticas sobre os processos de colonialidade, inspirados em concepções de conhecimento ocidental eurocêntrico, que se mostram ainda hegemônicos no país, a invisibilizar e aniquilar epistemes, fazeres e saberes alternativos e diversos. Para tanto, o percurso do ensaio trará reflexões sobre o modelo societário ocidental contemporâneo e as implicações que se produzem na esfera pública e nas intersubjetividades, tendo Hannah Arendt como interlocutora principal. A seguir, articulará uma antropologia do neoliberalismo com o conceito de necropolítica, através de Wacquant e Mbembe. Por fim, será realizado uma dialogia crítica entre este modelo societário e epistêmico hegemônico com uma epistemologia afrodiaspórica em solo brasileiro.

\section{Palavras chave}

1| neoliberalismo 2 | necropolítica 3| epistemologias afrodiaspóricas

\section{Cita sugerida}

Bonetti Lima, Alexandre (2021). Contemporaneidade neoliberal e epistemologias afrodiaspóricas: diálogos críticos em busca de novos devires. Tramas y Redes, (1), 121-141, 106a. DOI: 10.54871/cl4c106a

(c) Esta obra está bajo licencia Creative Commons Atribución-NoComercial-Compartirlgual

cc 4 BY NC SA 4.0 Internacional https://creativecommons.org/licenses/by-nc-sa/4.0/deed.es_AR 
Tramas y Redes Dic. 2021 $\mathrm{N}^{\circ} 1$

ISSN en trámite

\title{
Contemporaneidad neoliberal y epistemologías afrodiaspóricas: diálogos críticos en busca de un nuevo devenir
}

\section{Resumen}

Este ensayo tiene como objetivo esbozar consideraciones críticas sobre los procesos de colonialidad, inspiradas en concepciones del saber eurocéntrico occidental, que aún son hegemónicas en Brasil, y que invisibilizan y aniquilan epistemes, prácticas y saberes alternativos y diversos. Para ello, el desarrollo del ensayo traerá reflexiones sobre el modelo corporativo occidental contemporáneo y las implicaciones que se producen en la esfera pública y en las intersubjetividades, con Hannah Arendt como principal interlocutora. A continuación, se articulará una antropología del neoliberalismo con el concepto de necropolítica, a través de Wacquant y Mbembe. Finalmente, se producirá un diálogo crítico entre este modelo social y epistémico hegemónico con una epistemología afrodiaspórica en suelo brasileño.

\section{Palabras clave \\ 1| neoliberalismo 2| necropolíticas 3 | epistemologías afrodiaspóricas}

\section{Neoliberal contemporaneity and aphrodiasporic epistemologies: critical dialogues in search of a new becoming}

\begin{abstract}
This essay aims to outline critical considerations about the processes of coloniality, inspired by conceptions of Western Eurocentric knowledge, which are still hegemonic in Brazil, making invisible and annihilating alternative and diverse epistemes, practices and knowledge. To this end, the course of the essay will bring reflections on the contemporary Western corporate model and the implications that are produced in the public sphere and in intersubjectivities, with Hannah Arendt as the main interlocutor. Next, it articulates an anthropology of neoliberalism with the concept of necropolitics, through Wacquant and Mbembe. Finally, a critical dialogue between this societal and hegemonic epistemic model with an aphrodiasporic epistemology on Brazilian soil will be carried out.
\end{abstract}

\section{Keywords}

1| neoliberalism 2| necropolitics $3 \mid$ aphrodiasporic epistemologies 


\section{Introdução}

Até que os leões tenham seus próprios historiadores, as

Epistemologias, gnosiologias e práxis afrodiaspóricas no Brasil requerem especial atenção nos dias atuais. A violência com que pessoas de pele não branca são tratadas, a materializar índices escandalosos e revoltantes de desigualdade com relação aos brancos, seja nos dados de mortalidade e exposição à violência, como nos de renda, acesso à saúde, educação, moradia, dentre outros, que compõem, em conjunto, elementos de qualificação de uma vida cidadã, gritam aos ouvidos das gentes, e ainda mais intensamente nestes tempos de pandemia da Covid-19. No Brasil, a pandemia assume formas particularmente trágicas, ultrapassando a marca das 600.000 mortes, segundo Conselho Nacional de Secretarias de Saúde (consórcio nacional de veículos de imprensa com informações diárias extraídas das secretarias de saúde dos estados da federação).

A gravidade deste quadro social e sanitário e os seus impactos na vida das gentes, ampliam-se profusamente em razão do lamentável cenário político no país. Isto fica evidenciado nos crescentes obstáculos ao acesso aos serviços de saúde pública, em particular para a população pobre e negra, que chegou ao extremo nos momentos de colapso do sistema de saúde, com lotação e filas de espera para as vagas nos leitos hospitalares, além de falta de equipamentos cruciais para tratamento dos pacientes infectados pelo corona vírus (vide o intolerável episódio de falta de oxigênio na cidade de Manaus, a provocar a morte por asfixia em inúmeros pacientes). Também se revela no crescente processo de precarização das condições de trabalho e renda, através da flexibilização ainda maior das regulamentações trabalhistas, a retirar direitos consagrados dos trabalhadores com a justificativa de redução dos índices de desemprego que, no entanto, mantém-se em escala de crescimento, não obstante tais medidas. Revela-se, além disso, nas políticas de isolamento social e higienização das mãos não acompanhadas pela devida consideração e planejamento adequados, por parte dos órgãos públicos, para a melhoria das condições de moradia nas periferias urbanas, onde a população habita espaços extremamente acanhados, estreitos e apertados, muitas vezes sem acesso à água encanada, além da necessidade imperativa de sair às ruas para ganhar o sustento (home office não é uma escolha viável para essas pessoas). Também na restrição, quando não o total impedimento, de crianças e jovens às práticas educacionais devido ao não acesso (ou acesso precário) aos recursos necessários para as conexões do ensino remoto. Na considerável contração dos programas de proteção social para o 

desmantelamento de órgãos de fiscalização contra invasões ilegais de terras indígenas, a expandir os riscos de contaminação da população indígena pelo coronavírus. Tudo isso e tantas outras situações degradantes agravam e escancaram ainda mais um cenário de desigualdade e brutalismo social historicamente predominante no Brasil, ao qual se agrega - e é, ao mesmo tempo, consequência - ações políticas e comportamentos de um governo extremamente negligente e omisso com relação à saúde pública e às demandas sociais da população mais vulnerável, atento exclusivamente em manter-se no poder, aliando-se, para tanto, aos interesses das elites do grande capital financeiro, varejista e agroindustrial, além de brandir nacionalismos neofascistas e discursos supremacistas, articulados com governos e ideólogos de extrema direita, como armas para desviar a atenção da população de uma plutocracia patrimonialista e concentradora de riqueza.

Além disso, tem sido cada vez mais manifesto que o modelo de sociedade que preponderantemente orienta o desenvolvimento social, político e econômico - e não apenas do Brasil e da América Latina, mas da grande maioria dos países do mundo - mostra seu esgotamento, não somente no que diz respeito aos níveis de desigualdade abissal que produz, como também à devastação a toda a biosfera, às drásticas alterações climáticas, além do impacto desastroso a toda uma diversidade de áreas da vida em sociedade. É o nomeado mundo roto por Naomi Klein (2020).

Com efeito, alerta a autora que em meio ao advento da pandemia de Covid-19, mergulhamos globalmente em um cenário de crises que se revela com uma intensidade inédita na história recente, com um desmedido crescimento dos índices de desemprego, precarização do trabalho, pobreza e indigência, concatenados, ao mesmo tempo, com um crescimento desmesurado da concentração de riqueza. Como denuncia Klein (2020), enquanto os $20 \%$ mais endinheirados entre a população mundial detém $96 \%$ da riqueza, os $80 \%$ restantes amealham tão somente $4 \%$. Não bastasse a crise sócio-econômica ora vigente, a crise ambiental e sanitária vem lado a lado a uma crise civilizatória sem precedentes na história recente, a forjar perspectivas catastróficas, na medida em que uma crescente e vasta massa da população mundial se vê cada vez mais na condição de sobrante e descartável. Nas palavras da autora, "vítimas da dinâmica econômica imposta pelos grupos dominantes, agora não servem nem como mão de obra barata, que substituem por tecnologias, nem como consumidores por seus níveis de pobreza e indigência" (Klein, 2020, p. 27).

Este ensaio, diante disso, ambiciona, a partir de breves reflexões críticas sobre o modelo de sociedade predominante contemporaneamente - ocidental eurocêntrico e neoliberal - dialogar com saberes e fazeres desde há muito invisibilizados, em geral violentamente, de modo a se somar 
com um crescente movimento de rompimento com as certezas epistêmicas do provincianismo societário que impera na contemporaneidade, porque incapaz de abrir-se ao diálogo com as diversidades. Com efeito, Aníbal Quijano (2010), um dos expoentes do movimento decolonialista latino americano, argumenta que o colonialismo é o padrão mundial do capitalismo. Para ele, o capitalismo perpetua-se por intermédio da injunção de um paradigma que classifica a população mundial segundo critérios étnico-raciais, proporcionando a exploração e expropriação legitimada da colônia pelo colonizador. Com a criação da América, salienta o autor, o emergente sistema capitalista mundializa-se, forjando a modernidade e a colonialidade.

Mesmo após a independência formal dos países colonizados, Quijano (2010) denuncia a persistência do processo de colonialidade. Este, gerado pelas culturas coloniais e pelas estruturas do sistema-mundo capitalista moderno, permanece epistemológica e culturalmente hegemônico (Quijano e Wallerstein, 1992), além de impor relações de dependência econômica e política aos países periféricos, tais como os da América Latina e Caribe, África, entre outros.

Nessa medida, o ensaio busca somar-se às inquietações daqueles que, como o porto-riquenho Ramon Grosfoguel, perguntam:

Como é possível que o cânone do pensamento em todas as disciplinas das ciências sociais e humanidades nas universidades ocidentalizadas se baseie no conhecimento produzido por uns poucos homens de cinco países (França, Alemanha, Inglaterra, Estados Unidos e Itália)? Como é que no século XXI, com tanta diversidade epistêmica existente no mundo, estejamos ancorados em estruturas epistêmicas tão provincianas camufladas de universais? (Grosfoguel, 2016, p. 27)

A seguir, apresentamos algumas notas críticas sobre a contemporaneidade, as sociabilidades hegemônicas e suas implicações intersubjetivas.

\section{Contemporaneidade ocidental e a propagação do mal banal}

Para Hannah Arendt ([1958] 1993a), o que dignifica a condição humana é a política, pois seu verdadeiro significado, afirma, é a liberdade. Isso ocorre porque é na esfera política que homens e mulheres se ocupam dos assuntos públicos, em meio aos quais a inevitável diversidade das singularidades da pluralidade humana organiza-se mediante diálogos, negociações, debates, de modo a buscar produzir consensos mínimos. Dito de outra maneira, para Arendt ([1958]1993a), cada ser humano é único e a esfera política não deve omitir a existência dessa multiplicidade de eus, mas pelo contrário, o conflito, os diálogos e debates em torno das diferenças devem ser respeitados e 
reconhecidos, pois é em tais diferenças que se assenta o espaço público. A política, portanto, ocorre na diferença, combustível para a ação. Ao agir, o sujeito confirma sua singularidade, e volta-se para reclamar o direito à autonomia em nome da integridade do eu, mas só é de fato possível ao sujeito confirmar sua singularidade quando reconhece o outro como sujeito singular também, a despeito de suas diferenças. A produção da liberdade e da política, então, se processa na esfera pública, em meio aos conflitos, embates, negociações e diálogos, nunca encontrando um estado de equilíbrio estável e previsível, mas um continuado desequilíbrio e instabilidade entre consensos e desarranjos, concertos e desconcertos sociais em tempo.

Em A dignidade da política ([1961] 1993b), no entanto, Arendt reconhece um crescente processo, na modernidade, de desconfiança da dimensão política entre as pessoas. Assinala, sobre isso, que a depreciação da política tem como efeito a ausência da participação dos sujeitos na esfera pública, logo, uma tendência à atomização da sociedade. Em conjunturas como estas, denuncia a autora, de afastamento das pessoas da vida pública e da política, viabiliza-se a germinação de regimes autoritários e mesmo totalitários como o nazismo.

Com efeito, com o conceito de banalização do mal, Arendt ([1963] 2010) alega que o mal potencialmente pode ser realizado por qualquer pessoa. Seu argumento, contudo, não se assenta na tese de que a maldade faz parte da natureza humana, não é este ponto que lhe interessa, mas, como diz Márcia Tiburi “de uma compreensão do mundo no qual 'o outro' e mesmo o 'eu’ não importa tanto assim” (2014, pp. 47-48). A banalidade do mal, nesse sentido, configura-se mediante a ação performática de invisibilização da alteridade que torna o outro desimportante, sublinhado e tatuado reiteradamente como estrangeiro, como minoria abjeta ou, no mínimo, indiferente. A banalidade do mal é gerada, portanto, em meio a depreciação da esfera pública e da política, desdobrando-se potencialmente em uma sociedade de massas, ou seja, uma sociedade composta por indivíduos atomizados, logo, indiferentes e ausentes da responsabilidade sobre seus rumos.

Byung-Chul Han ([2015] 2019), do mesmo modo, assinala um processo de turvamento da alteridade nas sociabilidades contemporâneas como acontecimento do que denomina de sociedade da transparência. Nela, há um processo de igualitação de tudo e de todos como, simultaneamente, efeito e causa da eliminação da negatividade. Nas suas palavras:

As coisas tornam-se transparentes quando depõem sua singularidade e se expressam unicamente no preço. O dinheiro, que iguala tudo com tudo, desfaz qualquer incomensurabilidade, qualquer singularidade das coisas. Portanto, a sociedade da transparência é um abismo infernal do igual (Han, [2015] 2019, p. 10). 
De fato, a negatividade intrínseca da alteridade, a singularidade resistente do outro obstrui ou, no mínimo, retarda a velocidade da comunicação, a fluidez dinâmica das operações do capital, o fluxo vertiginoso das informações e a fugacidade das exposições de corpos e coisas formatados enquanto mercadorias-engrenagens para otimização do sistema. Vai-se alinhavando, assim, alega Han ([2015] 2019), um processo de degradação do campo social, a produzir, em seu lugar, uma atomização individualista, cujos elos de interação se enfraquecem crescentemente. Com efeito, diz o autor: "Tais egos não são singularidades que em comum podem oferecer resistência ao global. Ao contrário, todos eles são con-correntes, coatores e, ao mesmo tempo, vítimas do global; são microempreendedores que, entre si, apenas há possibilidade de uma relação de negócios” (p. 196).

A esse acontecimento, a essa reificação do humano que se alheia da esfera pública e da política atomizando-se, Arendt ([1961] 1993b) denunciou o vazio de pensamento, decorrência de um processo de dessubjetivação humana que se desdobra em - e é, ao mesmo tempo, desdobramento da supressão da alteridade. E sem alteridade, não há a negatividade intrínseca de singularidades em diálogo; sem dialogia com o outro, não há esfera pública, e tampouco sujeitos; e sem sujeito, não há pensamento reflexivo, apenas racionalidade técnica e positividade naturalizada, unívoca e transparente do jogo a ser jogado mesmo quando suas regras banalizam o mal.

Tal processo de reificação do humano, por sua vez, acelera-se como efeito da concorrência (des)esperada por espaços de inclusão em uma sociedade na qual o descarte de coisas e pessoas (corpos-mercadoria) é cada vez mais vertiginoso e evidente. Como lembra Zygmunt Bauman, em Vidas desperdiçadas ([2003] 2004), a virtualidade ameaçadora de ser descartado como refugo do sistema se faz presente em número cada vez mais vasto de pessoas, a configurar o que Achille Mbembe ([2013] 2018) denomina de devir negro, ou seja, a condição de ente abjeto e sobrante que se estende amplamente mundo afora a descolar-se da inexorável exclusividade da cor da pele negra e não branca. Nas palavras do autor:

Pela primeira vez na história da humanidade, o nome negro deixa de remeter unicamente para a condição atribuída aos genes de origem africana durante o primeiro capitalismo (predações de toda a espécie, desapossamento da autodeterminação e, sobretudo das duas matrizes do possível que são o futuro e o tempo). A este novo caráter descartável e solúvel, à sua institucionalização enquanto padrão de vida e à sua generalização ao mundo inteiro, chamamos devir negro do mundo (Mbembe, [2013] 2018, p. 18).

Este cenário de produção de humanos sobrantes, desdobramento da racionalidade capitalística, cujos paradigmas são ainda mais 
radicalizados com o advento da globalização neoliberal, tende a promover o desmantelamento irrefletido das possibilidades de construção autônoma das singularidades dos sujeitos, a aceitação alienada e acrítica das normatizações postas intersubjetivamente nos processos de subjetivação, cujo fundamento axial é a reprodução, multiplicação e concentração do capital financeiro. Paul Virilio e Sylvére Lotringer ([1981]1984) anunciam como efeito disso a produção do que denominam de transpolítica, que explicam como "o início do desaparecimento do político na rarefação da última provisão", a duração do tempo, acintosamente acelerado pela super velocidade dos fluxos digitais de informação (p.71). A transpolítica, então, materializa a morte da possibilidade da política baseada no diálogo, na dinâmica das trocas democráticas de argumentos, ideias e interesses na esfera pública, bem como na democratização do uso dos espaços, das técnicas e tecnologias, colonizadas que são pelo capital. Resistir à transpolítica e, deste modo, repolitizar o tempo, os lugares, as técnicas e tecnologias e seus respectivos usos, bem como as relações sociais nos mais diversos cotidianos é condição necessária para barrar os totalitarismos de uma sociedade de massa cuja globalização financeira apresenta-se como epicentro inquestionável.

\section{Neoliberalismo, globalização e necropolítica.}

No livro Contrafogos: táticas para enfrentar a invasão neoliberal, Pierre Bourdieu escreve:

Ouve-se dizer por toda parte, o dia inteiro, que não há nada a opor à visão neoliberal, que ela consegue se apresentar como evidente, como desprovida de qualquer alternativa. [...] Essa espécie de gota a gota simbólico, para o qual os jornais escritos e televisados contribuem muito fortemente, produz efeitos profundos. É assim que, no fim das contas, o neoliberalismo se apresenta sob as aparências da inevitabilidade (Bourdieu, 1998, pp. 43-44).

Congruente com isso, Milton Santos ([2000] 2010) denuncia as fábulas perversas da globalização neoliberal, lançadas frequentemente pelos meios de comunicação, a argumentar pela necessidade da redução drástica da intervenção do Estado no âmbito do mercado para que a liberdade e a democracia possam fortalecer-se, e a vida das pessoas, bem como a saúde das empresas, possam melhorar expressivamente. Por detrás destas fábulas, aponta Guareschi ([1994] 2013), há uma razão cínica e autoritária, que promove a naturalização de princípios de competitividade entre as pessoas, na medida em que concebe a meritocracia como peça categórica para abrir as portas para o sucesso de todas elas. Ela (a razão cínica neoliberal) alega, com tons de racionalidade - basta mirar os cadernos de economia de jornais 
impressos, digitais e televisivos, além de manuais líderes de venda de economia, administração e marketing - que a humanidade somente progrediu e poderá seguir em progresso em razão da competitividade. As tensões que provoca, justificam tais fábulas, favorecem a mobilização e a disciplina na inserção nas engrenagens do sistema para assim, virtualmente, serem adquiridos os méritos necessários para atingir o bem-estar social e o status de pessoas de bem e consumidoras qualificadas (Mansano e Lima, 2017). O Estado, aqui, deve restringir-se a um papel que não atrapalhe e não coloque obstáculos à liberdade da competitividade do mercado de pessoas e mercadorias.

Buscando construir uma antropologia histórica do neoliberalismo, Loïc Wacquant (2012) afirma que o núcleo institucional que o torna reconhecível "consiste numa articulação entre Estado, mercado e cidadania que aparelha o primeiro para impor a marca do segundo à terceira" (Wacquant, 2012, p. 509-510). O autor explica a designação deste núcleo institucional através de três teses. Na primeira tese, ele argumenta que o neoliberalismo é um projeto mais político do que econômico, o qual não objetiva o desmantelamento do Estado, como se tende a pensar, mas sua reengenharia. De fato, o Estado neoliberal reorienta-se no sentido de favorecer e fundamentar o mercado como criação política legítima e crucial. Substitui progressivamente, para tanto, os princípios do welfare state dos direitos sociais conquistados e concedidos por princípios corretivos e disciplinadores do workfare state, orientados pela flexibilização, terceirização, informalização do trabalho, redução salarial, entre outras formas de precarização das condições laborais e sociais (Wacquant, 2012).

$\mathrm{Na}$ segunda tese, Wacquant (2012) aponta a elaboração, pelo campo burocrático do neoliberalismo, do que denomina como Estado-centauro que, em suas palavras,

exibe rostos opostos nos dois extremos da estrutura de classes: ele é edificante e libertador no topo, onde atua para alavancar os recursos e expandir as opções de vida dos detentores de capital econômico; mas é penalizador e restritivo na base, quando se trata de administrar as populações desestabilizadas pelo aprofundamento da desigualdade e pela difusão da insegurança do trabalho e da inquietação técnica (Wacquant, 2012, p. 512).

A liberdade individual e de mercado, portanto, como celebram os defensores do neoliberalismo, é canalizada exclusivamente aos que têm o domínio do capital. Aos subalternos precarizados, contrariamente, resta a constrição dos movimentos e escolhas, e a exposição a ações, muitas vezes violentas, protagonizadas por agentes do Estado. 
Complementar à ideia de Estado-centauro neoliberal, a terceira tese defendida por Wacquant (2012) aponta o desenvolvimento, fortalecimento e ampliação do braço penal do Estado. Esta fica evidente no vasto crescimento da população encarcerada nos últimos anos. Nas palavras do autor: "Com poucas, parciais e preciosas exceções, o encarceramento cresceu rapidamente em todas as sociedades pós-industriais do ocidente, inchou nas nações pós-autoritárias da América Latina e explodiu nos Estados-nação oriundos do colapso do bloco soviético, à medida que faziam sua transição de economia de comando para a de mercado" (Wacquant, 2012, p. 513).

Em países de economia periférica, como o Brasil, associado ao expressivo crescimento do índice de detenções acusado pelo autor, as condições com as quais essa população vive nas prisões são de precariedade abominável: ambientes superlotados, imundos, repletos de enfermidades dos mais diversos tipos que assumem rapidamente proporções epidêmicas, brigas e assassinatos entre distintas facções, estupros, em suma, um processo de violenta desumanização imposta institucionalmente (Cardoso, Schroeder e Blanco, 2015).

Ainda no âmbito do braço penal do Estado, a polícia assume papel estrategicamente importante, na medida em que canaliza sua força e violência sobre as populações pobres das periferias. Com a justificativa de perseguição ao crime, penetram nos bairros periféricos e favelas das grandes cidades distribuindo tiros, invadindo casas, humilhando moradores e, invariavelmente, assassinando inúmeras pessoas, muitas delas crianças e adolescentes, tornando a história cotidiana das gentes que vivem nestas regiões uma permanente rotina de barbárie. Nada próximo às maneiras como a mesma polícia aborda bairros abastados. Em seu livro, Sobre o autoritarismo brasileiro (2019), Lilia Schwarcz denuncia que, entre 2011 e 2015, morreram 260 mil pessoas no conflito bélico da Síria, período no qual 270 mil pessoas foram assassinadas no Brasil. Relata ainda a autora que, nos vinte anos da guerra do Vietnã (1955-1975) foram mortas 1,1 milhão de pessoas em virtude do conflito; nesse mesmo intervalo de tempo, entre 1995 e 2015, foram assassinados 1,2 milhão de pessoas no Brasil. Desnecessário dizer que esses assassinatos têm cor de pele e território; concentram-se nas periferias e favelas das cidades brasileiras, cujos residentes são sobretudo pessoas de pele negra, e em parcela significativa protagonizados por agentes policiais. De fato, dados do Anuário Brasileiro de Segurança Pública, de 2015, apontam que apenas no estado do Rio de Janeiro, entre 2005 e 2014, o número registrado de homicídios provocados por policiais foi de 8.466. Entre as vítimas, não haviam residentes de bairros abastados, mas apenas pretos, pardos e pobres. Acrescente-se a isso o processo de genocídio já histórico aos povos indígenas, com a participação direta e indireta do Estado, tanto nas suas instâncias federal como estaduais e municipais, a desmantelar os órgãos de fiscalização 
e controle do desmatamento das florestas, de queimadas ilegais, da violenta invasão de terras indígenas por madeireiros, garimpeiros e mineradoras, além da suspensão de demarcação de novas terras para esses povos. Os processos de exclusão e matabilidade compõem-se com as ações do braço penal do Estado, correlacionando classe social e raça/etnia como alvos potenciais.

Fernando B. Gomes (2017), referindo-se à escala dos dispositivos estatais para produção de vidas sobrantes e descartáveis, utiliza-se do conceito de necropolítica de Mbembe. Se a biopolítica, como ressalta Michel Foucault (2008), materializa-se como modo de sujeição sutil, voltada para o controle e a produção calculista da vida, ela combina-se, nas esferas sociais periféricas, com a necropolítica mediante dispositivos complementares (Mbembe, 2018). Como estratégia mais radicalmente violenta, a necropolítica eleva a efetividade do controle biopolítico das populações ao demarcar os corpos marcados para morrer, invariavelmente, jovens e negros das periferias urbanas, além dos povos indígenas que obstaculizam a exploração desmedida das riquezas da floresta. De fato, afirma Gomes (2017, p. 57), “a governança necropolítica é sempre geográfica”. Ela espacializa os mecanismos da morte violenta das populações periféricas, concedendo à polícia a tarefa de matar, sem que isso seja qualificado como crime. No limite, pode-se sempre lançar mão do recurso jurídico do excludente de ilicitude. Basta relatar legítima defesa.

A necropolítica, porém, vai além da produção propriamente de cadáveres (Gomes, 2017). Ela segrega espacialmente pessoas e, simultaneamente, produz todo um conjunto de elementos discursivos, vocabulários e nomeações estigmatizantes gestando vidas nuas, ou seja, fazendo não mais somente morrer e tampouco viver, mas sobreviver, o que significa uma condição de vida despolitizada e desprovida de direitos (Agamben, [1995] 2010). Como alerta Djamila Ribeiro (2019), embora nos dias de hoje não seja mais declaradamente permitido expressar sentimentos de ódio e preconceitos contra pessoas negras, sob pena de acusação de racismo, nada proíbe que se odeie criminosos. Em um país ainda fartamente impregnado pelos espectros de uma matriz histórica escravocrata, violenta e patriarcal, não devidamente elaborada e sepultada, as qualificações negros, pobres e criminosos tendem a ser associadas irrefletidamente nos discursos midiáticos e no imaginário social, particularmente no nicho da população branca de classe média e abastada. A necropolítica, assim, materializa-se no dia a dia ordinário da vida sendo vivida das periferias brasileiras.

Em Crítica da razão negra ([2013] 2018), Mbembe afirma ser a necropolítica o modo de exercício da política mais compatível com o neoliberalismo, uma vez que responde aos seus principais objetivos. Como dito no início deste ensaio, no neoliberalismo contemporâneo a economia de mercado tende a generalizar-se para todo o tecido social, assumindo-se 
como princípio de inteligibilidade das sociabilidades e das práticas individuais de modo geral. Tudo pode ser mercantilizado, pois a tudo se pode estipular um valor de troca. Em uma sociedade na qual o princípio de inteligibilidade baseia-se no mercado, tudo o que é mercantilizado o é para ser consumido e, logo, ser também virtualmente descartado. Mas não são apenas commodities e artefatos industriais que entram no redemoinho do mercado das trocas e descartes. Também são cada vez mais descartadas as pessoas. Nas sociedades neoliberais contemporâneas, mercadorias humanas reificadas e desqualificadas (desnecessárias aos meios de produção) e consumidores falhos (sem recursos para entrar no universo dos que compram e fazem girar as engrenagens de uma economia impiedosa) tornam-se refugos inúteis (e matáveis).

Diante disso, resta-nos, como pesquisadores das humanidades, contribuir para a des-invisibilização de fazeres e saberes, epistemes e gnosiologias inclusivas, as quais, diferentemente do que é global e hegemonicamente posto, abrem brechas para a composição de modelos civilizatórios que contemplem e reconheçam as singularidades e outras possibilidades intersubjetivas. Enunciamos, a seguir, algumas considerações sobre epistemologias afrodiaspóricas em solo brasileiro que, como anuncia Eduardo David de Oliveira,

Tem como desafio a construção de mundos. Tem como horizonte, a crítica da filosofia dogmaticamente universalizante e como ponto de partida a filosofia do contexto. Intenta produzir encantamento, mais que conceitos, mudando a perspectiva do filosofar. Ambiciona conviver com os paradoxos, mais que resolvê-los. É mais propositiva que analítica. É singular e reclama seu direito ao diálogo planetário. Fala desde um matiz cultural, mas não se reduz a ele (Oliveira, 2012, p. 30).

\section{Algumas considerações sobre epistemologias afrodiaspóricas no Brasil: novas sociabilidades possíveis?}

Em sua obra, Poética da relação, Édouard Glissant escreve:

A experiência do abismo está no abismo e fora dele. Tormento daqueles que nunca saíram do abismo: que passaram diretamente do ventre do navio negreiro para o ventre violeta dos fundos do mar. Mas a sua provação não morreu, vivificou-se nesse contínuo-descontínuo: o pânico do país novo, a saudade da terra perdida, e pôr fim a aliança com a terra imposta, sofrida, redimida. A memória não 
sabida do abismo serviu de lodo para essas metamorfoses (Glissant, 2011, p. 19).

Glissant refere-se aqui à abominável experiência vivida pelos inúmeros negros africanos sequestrados em seus países de origem para serem vendidos, explorados e expropriados como escravos em terras estrangeiras deles completamente desconhecidas. Na travessia, muitos faleciam antes de chegar ao destino, tendo em vista as bárbaras condições e a extrema precariedade com que eram transportados nos porões dos navios que os traficavam. Uma vez mortos, ou ainda agonizantes, seus corpos eram jogados ao mar como lixos.

Os que sobreviviam à viagem, além de arrancados de suas terras e de suas redes de relações sociais e afetivas, eram despojados de sua autonomia, de seus corpos, cultura, nomes, língua, em suma, de sua humanidade, tornando-se propriedade de outrem. Alocados em terras estranhas e distantes, entre pessoas que falavam línguas desconhecidas - e não apenas os traficantes, capatazes e proprietários de escravos, mas também os outros negros escravizados, misturados que eram entre originários de diferentes nações africanas para evitar o planejamento de rebeliões coletivas e organizações de resistência - a saudade da terra de origem assumia uma força inexorável, tornando-se mote para reterritorialização na terra alheia, nos territórios da diáspora. Como diz Glissant,

[...] o ventre do navio negreiro é o lugar e o momento em que as línguas africanas desaparecem, porque nunca se colocavam juntas no navio negreiro, nem nas plantações, pessoas que falavam a mesma língua. O ser se encontrava dessa maneira despojado de toda espécie de elementos de sua vida cotidiana, mas também, e sobretudo, de sua língua (Glissant, 2005, p. 19).

$\mathrm{O}$ que acontece então com esse imigrante forçado, pergunta o autor? "Ele recompõe, através de rastros/resíduos, uma língua e manifestações artísticas, que poderíamos dizer válidas para todos" (Glissant, 2005, p. 19). Em outros termos, ele busca reterritorializar-se resistindo, desse modo, ao processo de desumanização que lhe é imposto barbaramente. A noção de rastros/resíduos, por sua vez, parece dialogar com a ideia de acontecimento de Muniz Sodré (2017). Nela, o autor remete a uma dinâmica que relaciona o trauma de toda a violência material e simbólica da escravização com a busca pela restauração da arkhé (a unidade do fundante, o sentido original e imaterial do mundo, cujos conteúdos são singulares conforme cada cultura) mediante a reorganização e reatualização do acontecimento originário. A reorganização do acontecimento se faz em meio às relações entre os vários coletivos de pessoas escravizadas originárias de distintas nações africanas, 
Nessas [as senzalas], onde se misturavam africanos de diferentes procedências étnicas a um contingente de indígenas, a fim de evitar rebeliões que pusessem seriamente em perigo a vida de seus proprietários, numericamente inferiorizados e estabelecidos em áreas interioranas isoladas, a necessidade de comunicação entre povos linguisticamente diferentes deve ter provocado a emergência de uma espécie de língua franca, que chamaremos dialeto das senzalas ([1993] 2020, pp. 69-70).

Crioulização, vale ressaltar, não deve ser confundida com mestiçagem. Mestiçagem é uma mistura de elementos distintos, cujo resultado é previsível e comensurável. Diferentemente, na crioulização os elementos que se inter-relacionam intervalorizam-se mutuamente gerando resultados imprevisíveis, imponderáveis e em constante transformação (Glissant, 2005), tal qual um caleidoscópio cujas figuras de sentidos ético-estéticos redesenham-se incessantemente. As línguas arcaicas africanas, por exemplo, trazidas com as pessoas originárias daquele continente e aqui escravizadas, “atualizaram-se no seu próprio hall linguístico interno, quando atualizaram o português falado no Brasil, abrindo para uma polifonia de sentidos que inverte a lógica da língua dominante. Palavras como mandinga, maloqueiro, calunga, ginga testemunham a favor dessa teoria" (Oliveira, 2012, p. 39). 
Consonante com isso, José Miguel Wisnik (2008), em estudo sobre a história do futebol no Brasil, destaca que quando foi introduzido no país, era um esporte praticado exclusivamente pela elite branca. Na proporção em que negros e mestiços foram gradativamente compondo as equipes nas competições que haviam, trouxeram para dentro do jogo saberes e fazeres ancestrais de um corpo que aprendeu, por gerações, a gingar para sobreviver às graves fatalidades e violências de um racismo estrutural que permanece, mesmo depois de findo o regime escravocrata. A capoeira e os diversos ritmos e danças afro-brasileiros foram referências importantes nesse processo, a incorporar seus saberes e inteligência corporais para confeccionar manobras e estratagemas astutos para o melhor enfrentamento dos adversários, melhor dizendo, a incorporar o drible, a ginga, a ludicidade no universo deste jogo. Referindo-se ao drible e à ginga, Wisnik (2008) define-os como ação que ocorre de maneira não linear, assumindo a forma de elipse, que é "finta, negaceio, sugestão de um itinerário que não se cumpre e que explora o efeito surpresa advindo, promessa de movimento que não se dá se dando e que se dá não se dando, alusão a gestos que se insinuam e se omitem em fração de segundos, de modo a aproveitar a perturbação da expectativa provocada" (Wisnik, 2008, p. 311). O futebol que, até então, caracterizava-se como esporte linear, que se fazia avançar sobretudo em linha reta, seja mediante os passes aos companheiros de equipe, os chutes a gol, seja por meio dos avanços sobre o adversário, ganha curvas e efeitos nos passes e chutes a gol, e a forma elíptica, que subtrai para adicionar, quando usa do drible e ginga para superar o adversário.

Tal qual o pássaro do mito de Sankofa, originário dos povos de língua Akan, da África Ocidental, cujo corpo é desenhado de forma a estar direcionado para a frente com a cabeça voltada para trás com algo no bico - como a buscar alguma coisa que ficou para trás para continuar a caminhada -, a ancestralidade ressignifica e atualiza, simultânea e reiteradamente, o presente e o passado, a fomentar um elo estreito entre o ontem e a atualidade. Nesse redesenho contínuo e dinâmico de passado e presente, intimamente articulados e mutuamente transfigurados/transfigurando-se, a ancestralidade mostra-se como ferramenta de orientação das relações na vida sendo vivida, a fomentar o processo de crioulização. Ferramenta que, por sua vez, ressignifica-se e transforma-se em tempo em meio às relações.

Nessa medida, a crioulização requer a noção de relação, e anuncia a falácia da essência, da identidade raiz, da ideologia do uno, próprias das civilizações de inspiração eurocêntrica. Como diz Enilce Rocha (2002, p. 34): “A relação pulveriza as ideias de Ser e de Essência”. O Ser, então, torna-se Sendo, Sendo em Relação. A Identidade raiz, por sua vez, a partir de cuja semente pressupõe-se a inevitabilidade do formato essencial da árvore madura, torna-se Rizoma que tece caminhos e formatos imprevisíveis em 
meio aos encontros e desencontros que vive/experimenta em tempo, tal como o herói sem caráter criado por Mário de Andrade, Macunaíma. Sem caráter não por ser imoral, mas por tecer rizomaticamente trajetórias diversas e insondáveis à rigidez característica dos heróis ocidentais, ora transformando-se em pássaro, ora em árvore, ora mimetizando e simulando-se em figuras e personagens múltiplos, ora falecendo e revivescendo mediante encantamentos e feitiços, brincando e amando sempre com belas cunhãs (Andrade, [1938] 2008).

A categoria de relação na epistemologia afrocêntrica, evoca inexoravelmente a categoria de ancestralidade, pois, como ressalta Oliveira (2007, p. 257), "não há ancestralidade sem alteridade". E a alteridade, por sua vez, não se conjuga no singular, ela requer, melhor dizendo, ela exige a relação com o Outro. Este é o fundamento sociológico da ancestralidade (Oliveira, 2012). Por seu vínculo inexorável com a relação, a ancestralidade não pode ser confundida com a tradição, nem tampouco com o folclore, pois não se aferra ao passado, mas o ressignifica e simultaneamente atualiza o presente reiteradamente, promovendo assim um elo íntimo e indissociável entre ambas as temporalidades. Como diz Oliveira (2012, p. 40), "fruto do agora, a ancestralidade ressignifica o tempo do ontem. Experiência do passado ela atualiza o presente e desdenha do futuro, pois não há futuro no mundo da experiência. A cosmovisão africana é, então, a epistemologia dessa ontologia que é a ancestralidade".

Por seu vínculo indefectível com a relação, ademais, a ancestralidade radicaliza o reconhecimento da diversidade. A unidade aqui, ressalta Oliveira (2012), consiste apenas na unidade de coexistência no mundo, de resto "o mundo é diversidade plena" (Oliveira, 2012, p. 41). A ancestralidade é, portanto, uma experiência ética, mais do que uma teoria do conhecimento, uma religião, uma política, ou uma moral, na medida em que germina uma circularidade inclusiva. Como diz Oliveira (2007, p. 257), "fla é o mar primordial donde estão as alteridades em relação", e se ancora em formas culturais inclusivas como a capoeira Angola, o Candomblé, as rodas de samba, as práticas de solidariedade comunitárias nas favelas urbanas, entre outros.

No que se refere ao samba, diz Muniz Sodré ([1998] 2015, p. 58):

Sabe-se que a estrofe solista improvisada, acompanhada de um refrão fixo (retomado pelo coro), é uma das principais características da música negro-brasileira. Tal era a forma do samba-de-morro tradicional. De fato, antigamente, os sambistas compunham só a primeira parte da canção (samba-de-primeira-parte), reservando à segunda um lugar de resposta social: ora o improviso na roda de samba, ora o improviso dos diretores de harmonia na hora do desfile da escola. 
O samba, assim, mais do que uma estética musical que entretém, é a ambiência a partir da qual intercâmbios de opiniões, ideias, desejos e desencantos de uma fala negra, como diz Sodré ([1998] 2015), se realizam e se acolhem em um círculo comunal, coletivo e inclusivo, no qual todos e Dic. 2021 todas participam do processo de sua construção, a unir, em estética unificada, o ritmo, a melodia, a letra e a dança. Nessa medida, ele resiste à ideologia produtiva dominante, que impõe peças prontas e acabadas.

Glissant $(2005,2014)$ utiliza-se das paisagens geográficas como metáforas para contrapor epistemes colonial-eurocêntricas, pautadas na ontologia da identidade-raiz e das essências individualizadas, com epistemes baseadas na ontologia da ancestralidade e das intersubjetividades rizomáticas das culturas compósitas decorrentes das diásporas. Às primeiras, ele batiza de pensamento continente, às outras de pensamento arquipélago. Diferentemente do continente, cujo território é único, o arquipélago é composto por uma multiplicidade de ilhas diversas que se circunvizinham, conformando-se em diferentes territórios que se interligam e mantêm-se em constante relação. $\mathrm{O}$ arquipélago aqui, vale ressaltar, enquanto metáfora não é simplesmente espaço físico, mas imaginário; imaginário que propicia o engajamento na diversidade, na imprevisibilidade do múltiplo, na crítica ao uno e às genealogias formatadas em cronologias lineares. O pensamento arquipélago, portanto, remete à ideia do sendo em relação com o que Glissant denomina Todo-O-Mundo, onde o Todo-O-Mundo realiza-se metaforicamente a partir do conjunto das ilhas (Ferreira e Oliveira, 2018). Desse conjunto em relação se faz a metáfora do Todo-O-Mundo. Diz Glissant (2014, p. 44) sobre isso: "O pensamento arquipelágico é totalmente oposto dos pensamentos de sistema. Ele se harmoniza ao tremor do nosso mundo. trámite O Todo-O-Mundo, o objeto mais alto de poesia, é, também o imprevisível. Nisso, ele é Caos-Mundo". É caos porque é devir, devir que se materializa em meio às relações, a partir das quais se negociam, tensionam-se, conflitam-se, dialogam-se, encontram-se e desencontram-se sem, contudo, ocorrer a diluição de uns pelos outros, sem a violência colonizadora, pois é nas zonas intersticiais, nos hiatos, nas fendas do entre que o devir se faz, a inventar povos, histórias, culturas, utopias, liberdade; a inventar e erigir mundos muito mais do que conceitos, que aprisionam e desencantam porque simplificam negando a complexidade; a erigir mundos que, portanto, reencantam-se ao abrir-se para o reconhecimento do outro em circularidades de relações inclusivas. "A relação liga, religa, relata. Ela não relaciona isto com aquilo, mas o todo ao todo. A poética da relação realiza, assim, o diverso. A raiz única mata à sua volta. A identidade-relação autoriza infinitamente" (Glissant, 2014, p. 44-45). 


\section{Considerações provisórias e introito disparador}

Problematizar, promovendo diálogos críticos, o pensamento hegemônico com epistemologias invisibilizadas, como as afrodiaspóricas, produz ressonâncias importantes para o campo de conhecimento acadêmico, majoritariamente preso ao pensamento canônico dos cinco países citados por Grosfoguel (2016) mais acima. Tais epistemologias devem ser impulsionadas densamente. Como denunciou Foucault (2010), referindo-se à Psicologia, esta ocupou preponderantemente a atribuição de instrumento de governamentalidade, a produzir saberes e discursos voltados para o fim de docilizar e domesticar a população. Pode-se tecer críticas semelhantes também à Antropologia, à Sociologia, à História, entre outros campos de conhecimento. A partir de tal função, tais disciplinas contribuíram para referendar epistemicídios, ou seja, aniquilar e invisibilizar conhecimentos e práxis das regiões periféricas do sistema-mundo detentoras de saberes e fazeres distintos do modelo hegemônico eurocêntrico capitalístico. Desempenharam, portanto, papel relevante no processo de colonização do pensamento, abrindo-se pouco a maneiras diversas de pensar, dialogar e intervir. Com poucas exceções, o cânone do pensamento nos cursos de formação nas Ciências Humanas permanece majoritariamente restrito às concepções teórico-metodológicas eurocêntricas e americanocêntricas. Mesmo quando se utiliza de autores críticos, suas referências, via de regra, restringem-se aos oriundos destas regiões do mundo, o que, segundo Spivak (2010), acaba por enveredar para uma violência epistêmica. Com efeito, argumenta a autora, o outro como sujeito é inacessível ao intelectual ocidental dos países centrais, pois em seu diagnóstico epistemológico ele projeta seu próprio etnocentrismo ao projetar a alteridade criando uma performance política de substituição (Spivak, [1999] 2010). Em outros termos, a violência epistêmica opera e se efetiva pelo intelectualismo que conjectura poder falar em nome do outro, o aludido oprimido, funcionando então, mesmo que involuntariamente, como cúmplice e reprodutor do colonialismo.

Diante disso, este ensaio pretende apresentar-se mais como um introito, inspirado em práxis e epistemologias afrodiaspóricas descoloniais - ainda repleto de questionamentos e incertezas -, de modo a somar-se a um movimento crescente, embora ainda reduzido, de desgarramento dos grilhões da colonialidade, de modo a reconhecer-se e se anunciar como resistência a pautar-se em considerações que declaram “(...) a importância de fazer circular dimensões teóricas e práticas críticas aos modos colonizados de produzir conhecimento e de intervir, bem como articular perspectivas engajadas que se propõem transformadoras da realidade" (Carvalhaes e Lima, 2020, p. 67), comprometendo-se politicamente com as vidas cotidianas, e orientando-se para desconstrução de discursos e ideologias que naturalizam a opressão e justificam a produção de desigualdades. O que pressupõe 
reconhecer e dialogar com a pluralidade viva e incalculada de saberes e fazeres que compõem a dinâmica da história das experiências e interações do cotidiano da vida sendo vivida em cada lugar.

\section{Referências}

Agamben, Giorgio ([1995] 2010). Homo Sacer: o poder soberano e a vida nua I. Belo Horizonte: Editora UFMG.

Andrade, Mario de ([1938] 2008). Macunaíma: o herói sem nenhum caráter. Rio de Janeiro: Agir.

Arendt, Hannah ([1963] 2010). Eichmann em Jerusalém: um relato sobre a banalidade do mal. São Paulo: Companhia das Letras.

Arendt, Hannah ([1958] 1993a). A condição humana. Rio de Janeiro: Forense Universitária.

Arendt, Hannah ([1961] 1993b). A dignidade da política. Rio de Janeiro: Relume Dumará.

Bauman, Zygmunt ([2003] 2004). Vidas desperdiçadas. Rio de Janeiro: Jorge Zahar Editor.

Bourdieu, Pierre (1998). Contrafogos: táticas para enfrentar a invasão neoliberal. Rio de Janeiro: Jorge Zahar Editor.

Cardoso, Silvio; Schroeder, Bruno e Blanco, Vera B. (2015). Sistema prisional e direitos humanos: a (in)suficiente responsabilização do Estado brasileiro. Revista Eletrônica de Direito Internacional, Belo Horizonte, 15, 1-31.

Carvalhaes, Flávia F. e Lima, Alexandre B. (2020). Contemporaneidade e decolonialismo: notas para uma práxis crítica e situada para a psicologia social. Revista Espaço Acadêmico, (223), Jul/Ago.

Ferreira, Luis Carlos e Oliveira, Eduardo David (2018). As filosofias negro africanas como arquipélagos de libertação. Odeere: Revista do Programa de Pós-Graduação em Relações Étnicas e Contemporâneas - UESB, 3(6), Jul/Dez.

Fórum Brasileiro de Segurança Pública (2015). Anuário Brasileiro de Segurança Pública, Ano 9.

Foucault, Michel (2008). Segurança, território, população: curso dado no Collège de France (1977-1978). São Paulo: Martins Fontes.

Foucault, Michel ([1974] 2010). Os anormais: curso dado no Collège de France (1974-1975). São Paulo: Martins Fontes.

Glissant, Edouard (2014). O pensamento do tremor. Juiz de Fora: Editora UFJF.

Glissant, Edouard (2011). Poética da relação. Portugal: Porto Editora.

Glissant, Edouard (2005). Introdução a uma poética da diversidade. Juiz de Fora: Editora UFJF. 
Gomes, Fernando B. (2017). Escalas da necropolítica: um ensaio sobre a produção do "outro" e a territorialização da violência homicida no Brasil. Geografia, Ensino e Pesquisa, 21(2), 46-60.

Grosfoguel, Ramon (2016). A estrutura do conhecimento nas universidades ocidentalizadas: racismo/sexismo epistêmico e os quatro genocídios/epistemicídios do longo século XVI. Revista Sociedade e Estado, 31(1), Jan/Abr.

Guareschi, Pedrinho ([1994] 2013). Pressupostos psicossociais da exclusão: competitividade e culpabilização. Em Sawaia, Bader B. (org). As artimanhas da exclusão: análise psicossocial e ética da desigualdade social (pp. 143-157). Petrópolis: Vozes.

Han, Byung-Chul ([2015] 2019). Sociedade da transparência. Petrópolis: Vozes.

Klein, Naomi (2020). Los años de reparación. Buenos Aires: CLACSO.

Mansano, Sonia Regina V. e Lima, Alexandre B. (2017). É melhor viver do que ser feliz: felicidade, idealização e consumo. Revista Espaço Acadêmico, 17(193).

Mbembe, Achille. ([2013] 2018). Crítica da razão negra. São Paulo: n-1 edições.

Moura, Clóvis ([1993] 2020). Quilombos: resistência e escravismo. São Paulo: Expressão Popular.

Oliveira, Eduardo David (2012). Filosofia da ancestralidade como filosofia africana: educação e cultura afro-brasileira. Revista Sul-Americana de Filosofia e Educação, (18), 28-47, mai/out.

Oliveira, Eduardo David (2007). Filosofia da ancestralidade: corpo e mito na filosofia da educação brasileira. Curitiba: Gráfica e Editora Popular.

Quijano, Aníbal (2010). Colonialidade do poder e classificação social. Em Santos, Boaventura de S. e Meneses, Maria Paula (org). Epistemologias do Sul (pp. 73-97). Petrópolis: Vozes.

Quijano, Aníbal e Wallerstein, Immanuel (1992). Americanity as a woncept or the Americas in the modern world-system. International Social Science Journal, 44(4), 549-557.

Ribeiro, Djamila (2019). Pequeno manual antirracista. São Paulo: Companhia das Letras.

Rocha, Enilce (2002). A noção de relação em Édouard Glissant. Ipotesi: Revista de Estudos Literários, 6(2), 31-39.

Santos, Boaventura de S. (2010). Para além do pensamento abissal: das linhas globais a uma ecologia de saberes. Em Santos, Boaventura de S. e Meneses, Maria Paula (org). Epistemologias do Sul. Petrópolis: Vozes. 
Santos, Milton ([2000] 2010). Por uma nova globalização: do pensamento único à consciência universal. Rio de Janeiro: Record.

Schwarcz, Lilia M. (2019). Sobre o autoritarismo brasileiro. São Paulo: Companhia das Letras.

Sodré, Muniz (2017). Pensar Nagô. Petrópolis: Vozes.

Sodré, Muniz ([1998] 2015). Samba, o dono do corpo. Rio de Janeiro: Mauad.

Spivak, Gayatri C. ([1999] 2010). Pode o subalterno falar? Belo Horizonte: Editora UFMG.

Tiburi, Marcia (2014). Filosofia prática: ética, vida cotidiana, vida virtual. São Paulo: Record.

Virilio, Paul e Lotringer, Sylvere ([1981] 1984). Guerra pura: a militarização do cotidiano. São Paulo: Brasiliense.

Wacquant, Loïc (2012). Três etapas para uma antropologia histórica do neoliberalismo realmente existente. Caderno $\mathrm{CRH}, 25(66)$, Set/Dez, 505-518.

Wisnik, José Miguel (2008). Veneno remédio: o futebol e o Brasil. São Paulo: Companhia das Letras. 